\title{
Dissemination and Implementation of a Community Wide Campaign Model to Improve Fruit \& Vegetable Intake and Physical Activity Among Mexican Americans in the Texas-Mexico Border Region
}

\author{
Belinda M. Reininger \\ UTSPH: The University of Texas Health Science Center at Houston School of Public Health \\ Lisa A. Mitchell-Bennett \\ UTSPH: The University of Texas Health Science Center at Houston School of Public Health \\ Minjae Lee \\ UT Southwestern: The University of Texas Southwestern Medical Center \\ Paul Gerardo Yeh ( $\square$ paul.yeh@utrgv.edu ) \\ The University of Texas Rio Grande Valley College of Health Professions https://orcid.org/0000-0002-3865-3010 \\ Tianlin Xu \\ UTSPH: The University of Texas Health Science Center at Houston School of Public Health \\ Amanda C. Davé \\ UTSPH: The University of Texas Health Science Center at Houston School of Public Health \\ Soo Kyung Park \\ UTSPH: The University of Texas Health Science Center at Houston School of Public Health \\ Alma G. Ochoa Del Toro \\ UTSPH: The University of Texas Health Science Center at Houston School of Public Health
}

\section{Research}

Keywords: Community-wide campaign, Community health worker, Fruit and vegetable consumption, Physical activity, Sedentary behavior, Behavioral dietary intervention, Dissemination and intervention research, Health disparities, Health behavior promotion, Mexican American community health, US-Mexico border health

Posted Date: May 4th, 2021

DOl: https://doi.org/10.21203/rs.3.rs-431499/v1

License: @) (1) This work is licensed under a Creative Commons Attribution 4.0 International License. Read Full License 


\section{Abstract \\ Background}

Evidence-based programs are slow to disseminate to create public health impact. Mexican Americans have low uptake of the modifiable healthy behaviors of fruit and vegetable (FV) consumption and physical activity (PA). This study analyzed the dissemination and implementation of an evidence-based community-wide campaign (CWC), Tu Salud ;Si Cuenta! (TSSC), in augmenting these behaviors among Mexican Americans living along the U.S.-Mexico Border.

\section{Methods}

We examined reach, effectiveness, adoption, implementation, and maintenance (RE-AIM) of the program. For effectiveness, participants were classified into "low exposure" and "high exposure" groups based on home visits by a community health worker (CHW). A dietary questionnaire and the Godin-Shepherd Exercise Questionnaire were used to quantify mean FV consumption and weekly PA level, respectively. Mean differences in change from baseline to follow-up was compared between the groups based on multivariable linear regression analysis, adjusting for age, gender, insurance and poverty status, and program components received. Odds of newly meeting FV and PA guidelines at follow-up were estimated with multivariable logistic regression analysis. All analyses were repeated for each location separately.

\section{Results}

Low-income Mexican-Americans ( $\mathrm{N}=8225)$ across twelve locations along the U.S.-Mexico border were analyzed. The program reached 2.2\% of the total population of the lower Rio Grande Valley region (Cameron and Hidalgo Counties, Texas). The high exposure group had significantly greater FV intake (adjusted mean difference $=+0.65 \mathrm{FV}$ servings, 95\% Cl: $0.53-0.77$ ) and PA (adjusted mean difference $=+185.6 \mathrm{MET}$-minutes, $95 \% \mathrm{Cl}$ : $105.9-265.4$ ) than the low exposure group. The high exposure group was significantly more likely to meet FV guidelines (adjusted odds ratio (AOR) $=2.03,95 \% \mathrm{Cl}$ : $1.65-2.47)$ and PA guidelines ( $A O R=1.36,95 \% \mathrm{Cl}$ : 1.10-1.68) at follow-up. In location-specific analysis, the association of increasing program exposure to degree of improvement in FV consumption and PA was replicated. 92.3\% (12/13) of locations offered the program adopted it. 58.3\% (7/12) of program locations implemented with fidelity, and $91.7 \%(11 / 12)$ maintained the program.

\section{Conclusions}

The results indicate this CWC intervention shows promise for improving health outcomes among low-income Mexican Americans in a scaled-up implementation effort. The adoption and maintenance of the program was strong, but staff capacity and turnover adversely impacted implementation fidelity.

\section{Trial registration:}

NCT03199365. Date: June 26, 2017

\section{Contributions To The Literature}

- The national priority of preventing chronic diseases among underserved populations requires broad implementation of evidence-based programs responsive to the complexities of lifestyle change in such populations.

- Dissemination and implementation research related to Latino health helps to promote health equity. Few systematic studies of a scaled-up communitywide campaign for low-income populations are available.

- This study reports factors influencing dissemination/implementation of the community-wide campaign in twelve low-income U.S.-Mexico border communities. Community health worker delivery and funding for implementation positively influenced reach, effectiveness, adoption, and maintenance, while lack of qualified community health workers and turnover negatively impacted the fidelity of implementation.

\section{Background}

Latinos, specifically Mexican Americans living on the U.S.-Mexico border in Texas have higher incidence and mortality rates of noncommunicable diseases (NCDs) paralleling those seen in developing, middle-income countries [1]. Individual-level lack of self-efficacy [2] and community-level built environment factors such as the lack of healthy food availability and physical activity infrastructure [3] precludes the uptake of modifiable health behaviors in Latinos, who thus are disproportionately not meeting the guidelines of consuming five servings of fruits and vegetables (FV) daily [4] nor achieving at least 150 minutes of moderate and vigorous physical activity (PA) weekly [5]. Consequently, this results in increased susceptibility to NCDs including Type 2 Diabetes Mellitus [6], hypertension [7,8], and cardiovascular disease [9,10], which culminate in increased all-cause mortality $[11,12,13]$.

In the U.S., a higher proportion of Latinos meet the recommended intake of fruits [14], and consume more FV servings than whites [15]; however, Latino mean FV intake is only $60 \%$ of the recommended guidelines $[11,16]$. Moreover, Latinos along the Texas-Mexico border are less likely to meet FV guidelines than the general American Latino population [1]. For Latinos living on the U.S.-Mexico Border, $80 \%$ of cardiovascular, diabetes, and stroke cases could be prevented by modifying health behaviors of FV consumption and PA engagement [17]. 
Latinos in the U.S. are less physically active than whites [3,6,18], with a higher proportion not meeting the aforementioned PA guidelines [19]. Physical inactivity rates are highest for those with less education [3], in poverty [19,20], or Latinas [21]. Additionally, Latinos living on the Texas-Mexico border were significantly less likely to meet PA guidelines compared to Latinos in the U.S. [1].

\section{Community-Wide Campaigns}

Community-wide campaigns (CWC) represent an evidence-based approach to improving FV consumption and PA engagement [22]. CWCs employ multicomponent, community-based interventions including media messages, social support, health education, risk factor screening, environmental infrastructure, and policy improvements in a cost-effective manner [22,23]. Some CWC interventions use theory such as the Transtheoretical Model [24,25,26], and Social Cognitive Theory [27,28,29] to tailor strategies to individuals [30], while also targeting other levels of influence from the socio-ecological model [31,32]. CWCs have shown improvement in PA in Koreans [26], Canadians [29], and Native Americans [33]. However, few CWCs targeting PAs have been published [34], and fewer have been based on behavioral theory [33]. CWC studies rarely focus on Southern/Eastern Europeans, Southern/Southeastern Asians, and American minorities that generally face more socioeconomic and community-level barriers that exacerbate health disparities [1,30]. One notable exemption is the Tu Salud iSi Cuenta! (Your Health Matters!) (TSSC) program designed to increase FV intake and intentional PA engagement in Mexican Americans living along the Texas-Mexico border [2,23,35,36]. The TSSC program demonstrated increased odds of meeting PA guidelines among Latino study participants compared to Latinos in a different border city without the program [23]. Also, exposure to the TSSC program was associated with meeting PA guidelines [35].

While CWCs are effective in improving outcomes, like many other evidence-based programs, the adoption and scale up of these programs at the population level takes far too long, even decades [37]. Program dissemination and implementation research seeks to enhance the spread of evidence-based interventions to priority populations by using planned strategies in response to the enormous gap between knowledge of what can maximize healthy outcomes and what is currently being delivered in community settings [38,39]. A critical research gap exists in the real-world implementation of CWC programs [30], with a particular lack of studies focused on vulnerable Latino populations. To date, with the exception of the North Karelia study which was later nationally disseminated [40,41], there has not been a study specifically examining the broad dissemination of a CWC program [42]. This study evaluates the dissemination of the evidence-based TSSC program to 12 municipalities on the Texas-Mexico border.

\section{RE-AIM Framework}

We used the RE-AIM (Reach, Effectiveness, Adoption, Implementation, and Maintenance) analytical framework [43] to evaluate the public health impact of the TSSC program between January 2014 - November 2019. The CWC model was originally developed and tested internationally and in the U.S. [2,23,36], and then adapted for Latinos in one city on the Texas-Mexico Border [35]. This study examines the dissemination of this program to 12 municipalities/precincts over two adjacent border counties. Our research questions include: 1) Reach - what percent of the population was reached by home visits conducted by TSSC community health workers (CHWs) and were participants low-income Latinos?; 2) Effectiveness - is the TSSC program significantly associated with improvements in FV and PA levels among participants across and by location?; 3) Adoption - what percent of communities offered the TSSC program adopted it?; 4) Implementation- what percent of locations implemented the program with fidelity?; and 5) Maintenance- what percent of locations maintained the program until the end of the study period?

\section{Methods}

\section{Study Context and Study Population}

All municipal and precinct locations involved in this study are located along the U.S.-Mexico border with Texas. The region is young (mean age of 45 years) [44] and rapidly growing [45], with a 2010 population of over 1.3 million, of which over $93 \%$ are Latino $[1,45]$. This area has over one third of the population living in poverty [46,47], with its per capita income half the American average [45], and low education levels [45].

As is common in persistent poverty regions, health disparities abound [47]. Over $28 \%$ of adults in the region have diabetes, and over $84 \%$ of adults are obese or overweight [48]. Additionally, nearly $67 \%$ of the adult population lacks health insurance [44].

\section{Implementing Locations}

The TSSC program has been disseminated and implemented in 12 locations. There were two county precincts with a population of 190,000 each, and ten municipalities included two major urban areas with a population of over 75,000 each ("City"), two small towns that ranged in population from 5,000 to 70,000 ("Town"), and six rural areas with populations of less than 5,000 ("Rural”) [49].

\section{Program Description and Implementation Over Time}

The Tu Salud ¡Si Cuenta! (Your Health Matters!) was initially designed for Latinos living in one border city to increase FV consumption and PA engagement $[2,50]$ and targeted psychosocial and environmental constructs that influence FV consumption and PA [2,51,52], including self-efficacy and cognitive and behavioral processes of change [2,35]. Social support and risk factor screening were provided during CHW home visits that included brief Motivational Interviewing strategies [53], which is an important component in behavior change [51,52]. TSSC used a community-engaged research approach to adapt the model to the cultural values of Mexican Americans on the Border [35]. Beginning in 2014, the TSSC program was expanded to other municipalities in the region using the core CWC model components (Table 1).

\section{Measures and Study Design}


The overall sample comprised of participants from across the twelve locations that were brought into the study between $2014-2019$ (Figure 1 ).

\section{Reach}

Reach was measured as the percent of the total population living in the municipalities and precincts that agreed to have program $\mathrm{CHW}$ follow-up visits to address risk factors. This measure of reach is conservative but accurate. The total population of the municipalities/precincts ("locations") was based on the 2018 American Community Survey [49] in the 12 locations as the denominator and the total unique TSSC program participants who received CHW home visits during the study timeframe as the numerator. We also examined reach by assessing the ethnicity and poverty status of participants.

\section{Socio-demographic characteristics}

Sociodemographic characteristics collected from the sample included: sex (male/female), age (respondent's date of birth), Latino (yes/no), health insurance (insured with government or private health insurance or uninsured), and income (above or below the federal poverty level [54]). Income level was based on two questions regarding household size and yearly household income. These variables were used to describe the reach of the program and in multivariable regression models of effectiveness.

\section{Effectiveness}

We assessed the effectiveness of the TSSC program by examining exposure to program elements and change in self-reported measurements of daily FV consumption and weekly PA. We classified the participants into two groups of "low exposure" (2-3 CHW visits) vs. "high exposure" (4-5 CHW visits) to define their exposure to the program.

\section{Fruit and Vegetable (FV) Consumption}

The validated Two-item Dietary Questionnaire for adults was used to assess FV consumption among participants, asking "How many portions of fruit, of any sort, do you eat on a typical day?" and "How many portions of vegetables, excluding potatoes do you eat on a typical day?" [55], with pictures of locally consumed fruits and vegetables to reflect recommended portion sizes [35]. The threshold for meeting current U.S. dietary recommendations was set at $5 \mathrm{FV}$ servings (3 cups of vegetables, 2 cups of fruits) daily [4].

\section{Physical Activity (PA)}

A modified version of the Godin-Shepherd Leisure-Time Exercise Questionnaire instrument [56,57] was used to measure the intensity, frequency, and duration of intentional PA. Weekly frequency of moderate or strenuous PA was multiplied by the minutes spent on each moderate or strenuous activity to calculate each participants' weekly metabolic equivalent adjusted minutes (MET-minutes). The metric for being "physically active" was quantified as meeting the U.S. PA recommendations of $\geq 600$ MET-minutes weekly [58], in tandem with prior exercise interventions [1,23,35,36,51,52].

\section{Participant Assignment to Locations}

Participants were classified by the geographic location they received TSSC program services. Almost exclusively, participants were seen within the jurisdictional boundaries of the $\mathrm{CHW}$ paid by that municipality or precinct. Three CHWs were hired by the university to deliver services across multiple locations; their participants were grouped by the participant's primary residence.

\section{Adoption}

Census data [49] were used to identify the total number of municipalities/precincts in the two-county region. We examined historical records of meetings and contracts for the number of municipalities/precincts offered the TSSC program and the number that implemented the program between January 2014 November 2019.

\section{Implementation}

Fidelity was based on evidence of reaching at least 35 participants with documented CHW home visits in the "high exposure" and "low exposure" categories to be included in the location-specific analysis. The programmatic electronic database that captured participant-level data by location was used to determine sufficient numbers of participants by site.

\section{Maintenance}

This was defined as the number of locations that adopted the program and had an active program including an employed CHW until November 2019.

\section{Statistical Analysis}

Guided by the RE-AIM Framework [43], the following approach to analysis was taken:

Reach: The percent of people who received CHW home visits over the total population of the 12 locations and the percent of the total participants who reported being low-income and Latino.

Effectiveness: We compared baseline characteristics of participants between two study groups ("low exposure" vs. "high exposure") using Student's $t$-test or its non-parametric equivalent (i.e. Wilcoxon rank sum test) for continuous variables and Chi-square test for categorical variables. To evaluate the program 
effects on increases in the amount of FV consumption or MET-minutes of PA, we calculated the changes in each outcome variable from baseline to the last $\mathrm{CHW}$ visit per participant. The changes from baseline to the last visit were compared between low and high exposure groups using multivariable linear regression models to examine the associations of program exposure with FV consumption or PA separately.

We also performed analysis for the subset of data from those who did not meet daily FV consumption recommendations or weekly PA guidelines at baseline, using logistic regression models to assess whether program exposure is associated with newly complying with FV or PA guidelines by the time of the last $\mathrm{CHW}$ visit. We further assessed the program effects by each location. While we conducted all aforementioned statistical analyses for each outcome variable, potential confounding effects such as participants' demographic characteristics were evaluated and adjusted accordingly in multivariable models. To account for heterogeneity among participants in their baseline measurement and duration of total follow-up, we adjusted for these variables in our analysis models. We also tested for effect modification to assess whether the program effects on behavior changes were modified by other variables. Underlying assumptions of linear regression and logistic regression were evaluated while developing final multivariable models. SAS software (SAS Institute Inc., version 9.4, Cary NC) was used to perform all statistical analyses with statistical significance level of 0.05 .

Adoption: The percent of total municipalities/precincts in the two-county region that were offered the intervention and adopted it.

Implementation: The percent of locations where $\mathrm{CHWs}$ delivered the program reaching at least 35 participants in the high and low exposure categories.

Maintenance: The percent of locations that adopted the program and had active programming until November 2019.

\section{Results}

\section{Reach}

The TSSC program was implemented across 12 locations with a cumulative population of 718,647 [49]. Between January 2014 and November 2019 , a total of 15,870 participants agreed to a follow-up visit by a CHW, or about $2.21 \%$ of the total population. Among participants who provided ethnicity data, 12,304 (93.25\%) identified as Latino, which aligns with the 12 locations' cumulative 91.3\% Latino population [45,49]. Among participants who provided both household size and income information, 8823 (81.18\%) were below the Federal Poverty Line [54], which is much higher than the $30.9 \%$ poverty rate in the study's twelve locations [49]. Finally, 8225 participants (81.91\%) who provided both ethnicity and income data were aligned with our priority population of Latinos with low income [54], which is much higher than the 12 locations' cumulative $32.9 \%$ Latino-specific poverty rate [49].

\section{Effectiveness Baseline Characteristics}

Among 15870 TSSC participants, those who had only one CHW visit ( $\mathrm{n}=9778,61.1 \%)$ were excluded from the analysis as no comparison follow-up measurement of FV consumption and PA from baseline could be examined. Non-Latinos ( $n=335,5.5 \%)$ and those who did not disclose their ethnicity ( $n=71$, $1.2 \%)$ were excluded from the analysis. A total of 5686 (36.0\%) participants were included in our analysis and were classified into "low exposure" ( $\mathrm{n}=4639)$ and "high exposure" ( $\mathrm{n}=1047)$ groups for analytical comparisons.

Baseline characteristics by exposure group are presented (Table 2). Median length of follow-up was 2.3 months (IQR= [1.1,5.1]) for the low exposure group, and 6.6 months (IQR= $[4.9,9.3])$ for the high exposure group. Participants in the high exposure group, compared to the low exposure group, did not differ significantly by age or sex (Table 2). The high exposure group was significantly more likely to have health insurance $(49.0 \%$ vs. $40.1 \%, p=0.0008)$ and be under the federal poverty level (FPL) $(76.6 \%$ vs. $84.2 \%$, p 0.0001$)$. In addition, at baseline, the high exposure group had significantly higher mean MET-minutes (306.3 vs. 166.4 MET-minutes, $p<0.0001$ ), mean FV consumption ( 3.4 vs. 3.2 servings, $p<0.0001$ ), and more people who met the PA guidelines (44.0\% vs. $37.9 \%, p=0.0004)$, and the FV consumption guidelines (27.5\% vs. $20.6 \%, p<0.0001)$ (Table 2$)$.

\section{Effectiveness Across Municipalities on Fruit and Vegetable Consumption}

The unadjusted and adjusted mean change in FV consumption from baseline to the last CHW visit were compared by low and high exposure group (Table 3). There was an increase in FV consumption from baseline to the last $\mathrm{CHW}$ visit in both exposure groups. We found that FV consumption increase from baseline to the last $\mathrm{CHW}$ visit in the high exposure group (+1.38 FV servings) was significantly higher than low exposure group (+0.73 FV servings) (adjusted mean difference $=+0.65 \mathrm{FV}$ servings, $95 \% \mathrm{Cl}$ : 0.53-0.77; $p<0.0001$ ) based on a multivariable adjusted model including confounders of participants' age, sex, insurance and poverty status, and the number of program components received (e.g. newsletter, exercise classes, newspaper, etc.) (Table 3). Additionally, participants with health insurance had significantly more FV consumption increase from baseline compared to those without insurance (adjusted mean difference $=+0.39 \mathrm{FV}$ servings, $95 \% \mathrm{Cl}$ : 0.29-0.49; $\mathrm{p}<0.0001$ ) (Table 3). There were no statistically significant associations found with age, gender, or poverty status of participants.

Out of 4411 individuals who did not meet FV guidelines at baseline, 946 (21.6\%) met the recommended FV guidelines by their last CHW visit (Table 4). The high exposure group had significantly higher odds of meeting FV consumption guidelines by the last CHW visit compared to the low exposure group (adjusted odds ratio $[A O R]=2.02,95 \% \mathrm{Cl}: 1.65-2.47 ; \mathrm{p}<0.0001)$ based on the multivariable logistic regression model, after controlling for aforementioned potential confounding effects (Table 4). Higher number of program strategies received (AOR 1.30, 95\% Cl: 1.22-1.39; p<0.0001), and having health insurance (AOR 1.24, $95 \% \mathrm{Cl}: 1.04-1.48 ; \mathrm{p}=0.0151)$ were significantly associated with a significant increased odds of complying with $\mathrm{FV}$ guidelines at the last $\mathrm{CHW}$ visit (Table 4). There were no statistically significant associations found with age, sex, or poverty status of study participants (Table 4). 
The mean change from baseline to the last CHW visit for PA (in MET-minutes per week) were compared between the low and high exposure group based on univariable (unadjusted) and multivariable (adjusted) linear regression models across all twelve locations (Table 3). There was an increase in MET-minutes PA from baseline to the last $\mathrm{CHW}$ visit in both exposure groups. The PA increase from baseline to the last CHW visit in the high exposure group (+396.3 METminutes) was significantly higher than the low exposure group (+210.7 MET-minutes) (adjusted mean difference $=+185.6$ MET-minutes, 95\% Cl: 105.9-265.4; $\mathrm{p}<0.0001$ ) based on multivariable models after controlling for potential confounders (Table 3). Higher number of program strategies received (+147.8 METminutes per additional program component, $95 \% \mathrm{Cl}$ : $120.8-174.7 ; \mathrm{p}<0.0001)$, younger age (-9.3 MET-minutes per year of age increase, $95 \% \mathrm{Cl}$ : -11.3 to -7.3 ; $\mathrm{p}<0.0001)$, and having health insurance (+161.7 MET-minutes, 95\% Cl: 95.1-288.3; $p<0.0001)$ were significantly associated with greater increase in PA level from baseline. No statistically significant associations were found with sex and poverty status (Table 3).

Among 3429 participants who did not meet PA guidelines at baseline, 1133 (33.3\% of the group) met PA guidelines by their last CHW visit (Table 4). The high exposure group had significantly higher odds of meeting PA guidelines by the last $\mathrm{CHW}$ visit compared to the low exposure group (AOR=1.36, 95\% Cl: 1.10 $1.68 ; p=0.0046$ ), based on the multivariable logistic regression model after controlling for potential confounding effects (Table 4). Higher number of program strategies received (AOR 1.18, 95\% Cl: 1.10-1.26; $p<0.0001$ ), female sex (AOR 1.35, 95\% Cl: 1.12-1.61; $p=0.0014$ ), and having health insurance (AOR 1.36, 95\% $\mathrm{Cl}: 1.15-1.63 ; p=0.0004)$ were significantly associated with increased odds of complying with PA guidelines. Older age and being in poverty (AOR $0.73,95 \% \mathrm{Cl}$ : $0.59-0.91 ; p=0.0005$ ) had significantly lower odds of complying with PA guidelines (Table 4).

\section{Effectiveness by Location on FV and PA}

As this is a study examining the dissemination of a model program to locations in a region, we examined the program effect by location where the sample size was greater than $n>35$ in either the high or low exposure group based on multivariable analysis (Table 5). One city (City B), two county precincts, and two rural municipalities (Rural E and Rural F) did not have enough sample size $(n>35)$ in the high exposure group to be included in the location-level program effectiveness analysis. Therefore, the adjusted mean changes in FV consumption and PA levels from baseline to the last $\mathrm{CHW}$ visit were compared between the low and high exposure group across seven different locations- one major urban area (City A), two towns (Town A, B), and four rural municipalities (Rural $A$, $B, C$, and D). The proportion of their sample that fell in the high exposure group varied greatly across locations and was documented as $27.7 \%$ of $n=1251$ (City A); $7.4 \%$ of $n=457$ (Town A); $11.0 \%$ of $n=747$ (Town B); $56.7 \%$ of $n=702$ (Rural A); $15.4 \%$ of $n=540$ (Rural B); $7.7 \%$ of $n=467$ (Rural C); $6.6 \%$ of $n=587$ (Rural D).

For FV consumption, in each of the municipalities there was an increase in FV consumption in both exposure groups at follow-up, and the high exposure group had significantly more increase in FV consumption compared to the low exposure group based on the adjusted model; for example, in Town A, the high exposure group had significantly higher increase in FV consumption compared to the low exposure group (adjusted mean difference= $+1.45 \mathrm{FV}$ servings, $95 \%$ Cl: 0.71-2.19; $\mathrm{p}<0.0001$ ) (Table 5). The high exposure group had higher odds of meeting FV consumption guidelines compared to the low exposure group in six of seven locations, with five locations meeting statistical significance (Table 5).

The mean changes from baseline to the last CHW visit for PA (in MET-minutes per week) were compared between the low and high exposure group in each location (Table 5). We found that the high exposure group had more increase in PA compared to the low exposure group in five of seven municipalities, including Town A which had an adjusted mean difference in change of +897.62 MET-minutes (95\% Cl: $541.05-1254.19 ;$ p $<0.0001)$. On the other hand, the high exposure group had a lower mean change of PA compared to the low exposure group in two locations: Town B (adjusted mean difference in change: -171.11 MET-minutes) and Rural B (adjusted mean difference in change: -147.53 MET-minutes), but these findings were not statistically significant (Table 5). We also found that the high exposure group had significantly higher odds of meeting PA guidelines by the last CHW visit compared to the low exposure group in six of seven municipalities, with three meeting statistical significance; in Rural $\mathrm{C}$, the high exposure group had significantly higher odds of meeting PA guidelines compared to the low exposure group (AOR 5.41, 95\% Cl: 1.62-18.08; $\mathrm{p}=0.0061$ ) (Table 5).

\section{Program Adoption}

During the first half of the study period (January 2014- December 2017), nine locations were offered the program and all nine adopted it in one county (100\% adoption rate). A total of 18 municipalities were in this county. Beginning August 2017, more locations were approached. One municipality (Rural F) was approached and adopted in the initial county. Three out of four precincts in a second county were contacted, and two implemented the program. The county precinct that did not agree to participate did not differ on sociodemographic variables such as racial composition or poverty rate as compared to the adopting precincts [49]. The overall adoption rate in both counties (adopted/approached) was $92.3 \%$

\section{Program Implementation}

Of the 12 locations that adopted, seven implemented with fidelity (58.3\%) by meeting the criteria to be included in the location-specific effectiveness analysis. The five locations that did not implement with fidelity included two locations with personnel issue (Rural E and City B), and the three locations that adopted in the second half of the study period. For example, one location (Rural F) did not begin participant enrollment until January 2019.

\section{Program Maintenance}

All but one location maintained the program (91.7\%) by having active programming until November 2019. Rural E discontinued the program due to personnel issues where qualified staff were not consistently available.

\section{Discussion}

In the literature, CWCs have been successfully adapted to promote health behaviors such as FV consumption [35,59] and physical activity engagement $[60,61]$ for the long-term management of chronic disease burden in communities, including among Latinos [2,23,35]. Indeed, the real-world implementation of 
evidence-based programs has the potential to improve public health. This study contributes to the literature by using the RE-AIM Framework [43] to examine the Reach, Effectiveness, Adoption, Implementation, and Maintenance of a CWC program implemented across multiple locations for a health disparate population of low-income Mexican Americans along the U.S.-Mexico border.

\section{Reach}

The "reach" of community-based interventions in the form of program enrollment of the priority population in need is not routinely reported [62,63], which limits the external validity and applicability of the findings of community interventions to other health disparate communities. Prior community-based health promotion interventions have found that minorities are less likely to meet eligibility criteria for enrollment and have differential attrition rates, thus culminating in participants of community-based interventions being wealthier, higher educated, and older than the target population of the intervention [62,63]. Within this study's five-year time frame, approximately $2.2 \%$ (over 15,000 ) of the total population in the participating region was reached with the program component that required enrollment and personalized $\mathrm{CHW}$ visits $[64,65,66]$. Unlike prior studies $[62,63]$, this intervention effectively enrolled the priority population for which programming services were designed. The goal of the TSSC program was to reach low-income Latinos and this was achieved with nearly $82 \%$ of the participants $(n=8225)$ fitting this criteria, which is far greater than our 12 locations' general $33 \%$ rate of low-income Latinos [49].

A noticeable issue with the reach and ultimately its effectiveness was that more than half of those reached by the program did not receive a follow-up CHW home visit. As the program retools implementation in the various locations, an emphasis on follow-up visits should be done. Overall, the reach results indicate that a CWC model appears to enroll low-income Latinos, which expands past literature showing CWC-based research being focused on primarily white, wealthier populations $[1,30,33]$.

\section{Effectiveness}

As evidence-based programs are implemented in real-world settings across varied locations, they need to remain effective at improving outcomes. We found significant improvement in FV consumption and PA aggregately across locations with those in the high exposure group having generally greater increases in FV consumption and PA MET-minutes than the low exposure group, but with both groups demonstrating improvement from baseline. Our study population was predominantly low income, uninsured, middle-aged Latinas and therefore our findings provide insight into improving nutrition and physical activity behaviors in this specific population. Additionally, our study parallels existing literature which suggests that CWC interventions in the Latino community that incorporate $\mathrm{CHW}$ outreach leads to improved behavioral outcomes and uptake [2,35].

Other CWC-based interventions globally also found improvement in nutritional choices including decreasing high-fat dairy [67,68], saturated fat [69,70], and red meat [71] in both developed and developing nations. We found some differential impacts based on sociodemographic factors. In particular, health insurance (government and private) was associated with significantly greater mean increases in FV consumption and PA MET-minutes and an increased odds of meeting FV and PA guidelines, after controlling for other confounders (e.g., age, sex, poverty status). The ability to afford or qualify for this type of coverage likely signifies more stable employment, higher socioeconomic status, and legal residency/citizenship status which enhances the ability to engage in this longitudinal program. Additionally, having insurance likely equates to individuals having more routine access to healthcare and thus exposure to healthcare providers and auxiliary staff who may also provide supplemental encouragement- beyond the scope of the program-for the participant to engage in healthier eating and PA behaviors. In general, our finding parallels past research among Latinos where having insurance has been associated with increased PA levels $[3,72]$.

Overall, our aggregate findings of effectiveness indicate that the program was disseminated and implemented in a manner that the two primary outcomes were achieved when individuals were exposed through $\mathrm{CHW}$ follow-up visits. Past research suggests that successful implementation of the CWC model appears to be related to implementation in communities with high needs [73]; our study results corroborate this finding.

We examined outcomes by location to further investigate effectiveness. Those participants who received high exposure to the program, across all locations, were significantly more likely to report improved mean change in FV consumption over baseline. Furthermore, in most locations, among those who did not meet the FV guidelines at baseline, their odds of meeting guidelines by last follow-up was robustly associated with having high program exposure versus low program exposure, regardless of setting. These findings suggest that programmatic engagement is associated with improvements to participants' FV consumption, thus highlighting the need to increase high levels of exposure to the program for more low-income Mexican Americans.

The results were more mixed in the location analysis for PA. Most locations (five of seven) demonstrated that high exposure was associated with increased MET-minutes of PA compared to the low exposure group, but only two of seven locations had statistically significant results. Overall, the difference in effect size by location is wide, differs by outcome, and is partially explained by individual and organizational capacity factors. The CHWs differed individually in their professional backgrounds and approach to follow-up visits. The implementing organizations differed in their approach to supervision and municipality priorities. As the $\mathrm{CHWs}$ balanced these factors, their time and emphasis on follow-up visits and programmatic content may have differed. Future research should examine these and other factors associated with the Implementation and Maintenance dimensions of the RE-AIM framework [43] more fully to particularly understand the variability in PA outcomes by location.

\section{Adoption}

The TSSC program was adopted by $92.3 \%$ of locations $(12 / 13)$ to which it was promoted. Our study reflects interest and motivation to adopt the program in a high need region. Enthusiasm for adoption was likely influenced by the presence of grant funding to cover annual program costs. Over time the local municipalities were able to leverage this core funding into additional programming and infrastructure improvements, which built enthusiasm. This then is the issue with public health funding for low resource regions; the need and willingness is there, but without funding the adoption of evidence based programs is curtailed. Generally, past research has indicated that community-based interventions are not adopted because health issues are not perceived by key 
stakeholders and municipal decision-makers as relevant [74,75,76]. Notably, the TSSC program builds upon prior local adoption of this program [2,23,35], and leverage those successes to create relevance, and handle perceived barriers and challenges to facilitate collaboration and program adoption.

\section{Implementation}

This scaled-up version of the TSSC program was implemented with fidelity in $58.3 \%$ of locations $(7 / 12)$. The program attempted to localize the CWC to each implementing location by tailoring to demographic profile, cultural values, and health issues. Discrepancies with implementation rests with personnel challenges that varied for each community. Locations that adopted the TSSC program with fidelity generally quickly identified CHWs with experience or capacity to implement program components; accordingly, these locations began their programming early in the study period. According to Knudsen et al. (2020), implementation fidelity can be enhanced personnel training, as well as routine (monthly) monitoring of the dosage of program components delivered, and adherence to program component protocols at each location [77]. With this iteration of the program, monthly CHW training sessions were conducted to enhance programming consistency, along with location-specific annual implementation evaluations. Future iterations of the TSSC program should further explore additional factors influencing implementation fidelity.

\section{Maintenance}

The program was ultimately maintained by $91.7 \%$ of locations (11/12) during the nearly five-year time frame. Indeed, maintenance was high, but like adoption, influenced by the presence of ongoing grant funding to support the intervention staff and activities. As the program is still currently active in the locations with future expansion planned, more knowledge about maintenance will come over time, as has been the case in the extensively studied original CWC program implementation in Finland which has been faithfully maintained in many communities for over 40 years [40,41].

\section{Limitations}

The limitations to our study include a lack of control communities, which had this been an efficacy study would be a substantial flaw. However, several previous studies with control groups on the TSSC program have shown evidence of efficacy [23,35,36], and this study focused on the real-world, scaled up dissemination and implementation of the program across an entire health disparate region. The results do advance the literature on CWC models to address FV consumption and PA in twelve locations advancing the knowledge of the reach, effectiveness, adoption, implementation, and maintenance of this model in real-world scenarios.

Another limitation is the difference in the sample size between the low and high exposure groups when examining program effectiveness. The high exposure group was smaller and the unequal sample size between these groups may have weakened the statistical power and did result in five of the twelve implementing locations being excluded from the analysis. As the programs develop and realize more participants in the high exposure group, and more participants who are followed for a longer timeframe, further analysis should be done to examine maintenance of the program using longitudinal analysis. Finally, as with many population studies, the outcome variables were measured through self-reported measures. These measures are subject to desirability bias and objective measures tend to be too costly for large populations [52]. Future research could consider a subsample cohort drawn that is followed with more complete measures such as the Automated Self-Assessment (ASA) for dietary intake information [78] or Accelerometers for physical activity assessment [52].

\section{Conclusions}

This study used the RE-AIM Framework [43] to evaluate a scaled-up CWC across twelve locations along the U.S.-Mexico border and uniquely contributes to the literature. Overall, this study demonstrates that the TSSC program reached its intended low-income Mexican American population who at baseline have low uptake of health behaviors including FV consumption and PA engagement [1, 17], which consequently culminates in a disproportionate burden of NCDs in this community [6-13]. The study showed effectiveness in its dose-dependent relationship between increased program exposure and degree of statistically significant increases in FV consumption and PA. The study also shows high adoption, moderate fidelity of implementation, and high maintenance across a variety of settings ranging from major urban to rural communities. Evidence-based, health behavior promotion interventions in Latino communities are limited in scope, with little published literature emphasis on the reach, adoption, implementation, or sustainability of the intervention [50]; accordingly, this study thus adds evidence to the literature about the successful implementation and dissemination of a regional scaled-up CWC to address behavior change in lowincome Mexican Americans in a health disparate region.

\section{Abbreviations}

AOR: Adjusted Odds Ratio

CHW: Community health worker

Cl: Confidence interval

CWC: Community-wide campaign

FPL: Federal poverty level

FV: Fruit and vegetable consumption

IQR: Interquartile range 
MET: Metabolic equivalent

NCD: Non-communicable disease

OR: Odds ratio

PA: Physical activity

RE-AIM: Reach, effectiveness, adoption, implementation, and maintenance analysis model

RR: Relative Risk

SPH: School of Public Health [University of Texas Health Science Center at Houston]

TSSC: Tu Salud ¡Si Cuenta! (Your Health Matters!) initiative

\section{Declarations}

\section{Ethics approval and consent to participate}

This research was approved by the University of Texas Health Sciences at Houston Institutional Review Board, the Committee for the Protection of Human Subjects (HSC-SPH-05-0488). Adults provided their written consent to participate.

\section{Consent for publication}

Not applicable.

\section{Availability of data and material}

The datasets generated during and/or analyzed during the current study are available from the corresponding author on reasonable request.

\section{Competing interests}

The authors declare that they have no competing interests.

\section{Funding}

The study was funded by the UT Health Center for Clinical and Translational Science Award (UL1 TR003167) and the Texas Health and Human Services Commission SNAP-Ed program.

\section{Authors' contributions}

BR contributed to the conception and design of the original study upon which this paper is based, and wrote all sections of the manuscript. LMB contributed to the conception and design of this study and writing portions of the methods and limitations section of the manuscript. ML, TX, and SKP contributed to the development of study measures, developed the analytical plan, conducted analyses for this paper, designed the manuscript tables, and prepared the results and analysis section of the manuscript. PGY performed a literature review, and assisted with the analyses for this paper, interpreting the data, reformatting and editing the tables, and was a major contributor in drafting and proofreading all sections of the manuscript. AD and AGODT oversaw acquisition of data, data entry, and contributed to the methods and limitations section of the manuscript. BR was the Principal Investigator of the original study. All authors read and approved the final manuscript.

\section{Acknowledgements}

The authors of this manuscript would like to acknowledge and thank the following funders, partners and staff. This work is partially funded by the UT Health Clinical and Translational Science Award (UL1 TR003167) and the Texas Health and Human Services Commission SNAP-Ed program. We would like to thank the following partners including the cities, towns and precincts of Brownsville, Combes, Harlingen, La Feria, Laguna Vista, Los Fresnos, Los Indios, Port Isabel, Rio Hondo, San Benito, Hidalgo County Precincts 1 and 4, and the Brownsville Wellness Coalition and Unidos Contra la Diabetes. The leadership, staff and community members in these locations and organizations care deeply about improving health. Thank you to My Own Med, Inc. that built and maintained the community-based data platform. Finally we would like to recognize staff on our University team including Marcelina Martinez, Alba Flores, Mirna Carrizales, Jessica Perez, Otila Estrada, and Alma Martinez.

\section{References}

1. Fisher-Hoch SP, Vatcheva KP, Laing ST, Hossain MM, Rahbar MH, Hanis CL, et al. Missed Opportunities for Diagnosis and Treatment of Diabetes, Hypertension, and Hypercholesterolemia in a Mexican American Population, Cameron County Hispanic Cohort, 2003-2008. Preventing Chronic Disease 2012;9:110298. doi: 10.5888/pcd9.110298

2. Heredia NI, Lee M, Mitchell-Bennett L, Reininger BM. Tu salud ¡Sí cuenta! your health matters! A Community-wide campaign in a Hispanic Border Community in Texas. Journal of Nutrition Education and Behavior. 2017;49(10):801-809.e1. doi: 10.1016/j.jneb.2017.06.008. 
3. Neighbors CJ, Marquez DX, Marcus BH. Leisure-time physical activity disparities among Hispanic subgroups in the United States. Am J Public Health. 2008;98(8):1460-4. doi: 2105/AJPH.2006.096982

4. US Department of Agriculture. 2015-2020 dietary guidelines for Americans. 8th ed. US Department of Agriculture. 2015. https://health.gov/dietaryguidelines/2015/guidelines/external icon. Accessed 10 May 2020.

5. Department of Health and Human Services (DHHS). Executive Summary: Physical Activity Guidelines for Americans, $2^{\text {nd }}$ Edition. DHHS. 2018. https://health.gov/paguidelines/second-edition/pdf/PAG_ExecutiveSummary.pdf. Accessed 18 May 2020.

6. Dunstan D, Barr E, Healy G, Salmon J, Shaw J, Balkau B, Magliano D, Cameron A, Zimmet P, Owen N. Television viewing time and mortality the australian diabetes, obesity and lifestyle study (AusDiab). Circulation. 2010;121(3):384-91. doi: 10.1161/CIRCULATIONAHA.109.894824

7. Warren TY, Barry V, Hooker SP, Sui X, Church TS, Blair SN. Sedentary behaviors increase risk of cardiovascular disease mortality in men. Med Sci Sports Exerc. 2010;42(5):879. doi: 10.1249/MSS.0b013e3181c3aa7e

8. Grøntved A, Hu FB. Television viewing and risk of type 2 diabetes, cardiovascular disease, and all-cause mortality: a meta-analysis. JAMA. 2011;305(23):2448-55. doi: 10.1001/jama.2011.812

9. Edwardson CL, Gorely T, Davies MJ, Gray LJ, Khunti K, Wilmot EG, et al. Association of sedentary behaviour with metabolic syndrome: A meta-analysis. PLoS One. 2012;7:e34916. doi: 10.1371/journal.pone.0034916

10. Reininger BM, Wang J, Fisher-Hoch SP, Boutte A, Vatcheva K, McCormick JB. Non-communicable diseases and preventive health behaviors: a comparison of Hispanics nationally and those living along the US-Mexico border. BMC Public Health. 2015;15:564. doi: 10.1186/s12889-015-1850-y

11. Colon-Ramos U, Thompson FE, Yaroch AL, Moser RP, McNeel TS, Dodd KW, Atienza AA, Sugerman SB, Nebeling L. Differences in Fruit and Vegetable Intake among Hispanic Subgroups in California: Results from the 2005 California Health Interview Survey. Journal of the American Dietetic Association. 2009;109(11):1878-1885. doi: 10.1016/j.jada.2009.08.015.

12. Loef $M \&$ Walach $H$. The combined effects of healthy lifestyle behaviors on all cause mortality: a systematic review and meta-analysis. Preventive Medicine. 2012;55:163-170. doi: 10.1016/j.ypmed.2012.06.017

13. Biddle SJ, Bennie JA, Bauman AE, Chau JY, Dunstan D, Owen N, Stamatakis E, van Uffelen JG. Too much sitting and all-cause mortality: is there a causal link? BMC Public Health. 2016;16(1):635. doi: 10.1186/s12889-016-3307-3

14. Lee-Kwan SH, Moore LV, Blanck HM, Harris DM, \& Galuska D. Disparities in State-Specific Adult Fruit and Vegetable Consumption- United States, 2015. Morbidity and Mortality Weekly Report. 2017;66(45):1241-1247. doi: 10.15585/mmwr.mm6645a1

15. Tichenor N \& Conrad Z. Inter- and independent effects of region and race/ethnicity on variety of fruit and vegetable consumption in the USA: 2011 Behavioral Risk Factor Surveillance System (BRFSS). Public Health Nutrition. 2016;19(1):104-113. doi: 10.1017/S1368980015000439.

16. Dietary Guidelines for Americans, 2005: US Department of Agriculture Web site. http://www.health.gov/dietaryguidelines/dga2005/document/pdf/DGA2005.pdf. Accessed 28 April 2020.

17. Ennis S, Rios-Vargas M, Albert N. The Hispanic Population: 2010. 2010 Census Briefs. 2011. United States Census Bureau. 2011. https://www.census.gov/prod/cen2010/briefs/c2010br-04.pdf. Accessed 17 May 2020.

18. Marquez DX, Neighbors CJ, Bustamante EE. Leisure time and occupational physical activity among racial or ethnic minorities. Medicine and Science in Sports Exercise. 2010;42(6):1086-93. doi: 10.1249/mss.0b013e3181c5ec05

19. Go AS, Mozaffarian D, Roger VL, et al. Heart disease and stroke statistics-2013 update: a report from the American Heart Association. Circulation. 2013;127(1):e6-245. doi: 10.1161/CIR.0b013e31828124ad

20. Eyler AA, Brownson RC, Bacak SJ, Housemann RA. The epidemiology of walking for physical activity in the United States. Basic Sciences: Epidemiology. 2003;35(9):1529-1536. doi: 10.1249/01.MSS.0000084622.39122.0C

21. Marcus BH, Hartman SJ, Larsen BA, Pekmezi D, Dunsiger SI, Linke S, Marquez B, Gans KM, Bock BC, Mendoza-Vasconez AS, Noble ML, Rojas C. Pasos Hacia La Salud: a randomized controlled trial of an internet-delivered physical activity intervention for Latinas. International Journal of Behavioral Nutrition and Physical Activity. 2016;13:62. doi: 10.1186/s12966-016-0385-7

22. Campaigns and Informational Approaches to Increase Physical Activity: Community-Wide Campaigns https://www.thecommunityguide.org/findings/physical-activity-community-wide-campaigns. Accessed 13 May 2020.

23. Heredia NI, Lee M, Reininger BM. Exposure to a community-wide campaign is associated with physical activity and sedentary behavior among Hispanic adults on the Texas Mexico border. BMC Public Health. 2017;17:883. doi: 10.1186/s12889-017-4893-4

24. Spencer L, Adams TB, Malone S, Roy L, Yost E. Applying the transtheoretical model to exercise: a systematic and comprehensive review of the literature. Health Promot Pract. 2006;7(4):428-43. doi: 10.1177/1524839905278900

25. Marshall SJ, Biddle SJ. The transtheoretical model of behavior change: a meta-analysis of applications to physical activity and exercise. Ann Behav Med. 2001;23(4):229-46. doi: 10.1207/S15324796ABM2304_2

26. Jo HS, Song YLA, Yoo S, Lee H. Effectiveness of a province-wide walking campaign in Korea on the stages of change for physical activity. Int J Sport Exerc Psychol. 2010;8(4):433-45. doi: 10.1080/1612197X.2010.9671962

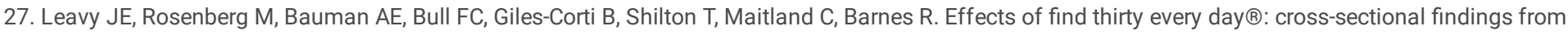
a western Australian population-wide mass media campaign, 2008-2010. Health Educ Behav. 2013;40(4):480-92. doi: 10.1177/1090198112459515

28. Sharpe PA, Burroughs EL, Granner ML, Wilcox S, Hutto BE, Bryant CA, Peck L, Pekuri L. Impact of a community-based prevention marketing intervention to promote physical activity among middle-aged women. Health Educ Behav. 2010;37(3):403-23. doi: 10.1177/1090198109341929

Page $10 / 16$ 
29. Jennings CA, Berry TR, Carson V, Culos-Reed SN, Duncan MJ, Loitz CC, McCromack GR, McHugh TLF, Spence JC, et al. UWALK: the development of a multi-strategy, community-wide physical activity program. Translational Behavioral Medicine. 2017;7(1):16-27. doi: 10.1007/s13142-016-0417-5

30. Gubbels JS, Mathisen FKS, Samdal O, et al. The assessment of ongoing community-based interventions to prevent obesity: lessons learned. BMC Public Health. 2015;15(1):1-11. doi: 10.1186/s12889-015-1563-2

31. Baker PRA, Francis DP, Soares J, Weightman AL, Foster C. Community-wide interventions for increasing physical activity. Cochrane Database Systematic Reviews. 2011;4:CD008366. doi: 10.1002/14651858.CD008366.pub2

32. Huang TT, Drewnosksi A, Kumanyika S, Glass TA. A systems-oriented multilevel framework for addressing obesity in the 21 st century. Preventing Chronic Disease. 2009;6(3):A82. https://www.ncbi.nlm.nih.gov/pmc/articles/PMC2722412/pdf/PCD63A82.pdf

33. Fleishhacker S, Robert E, Camplain R, Evenson KR, Gittelsohn J. Promoting Physical Activity Among Native American Youth: a Systematic Review of the Methodology and Current Evidence of Physical Activity Interventions and Community-wide Initiatives. Journal of Racial and Ethnic Health Disparities. 2016;3:608-624. doi: 10.1007/s40615-015-0180-1

34. Compernolle S, de Cocker K, Lakerveld J, Mackenbach JD, Nijpels G, Oppert JM, et al. A RE-AIM evaluation of evidence-based multi-level interventions to improve obesity-related behaviours in adults: a systematic review (the SPOTLIGHT project). Int J Behav Nutr Phys Act. 2014;11:147. doi: 10.1186/s12966014-0147-3

35. Reininger BM, Mitchell-Bennett L, Lee M, et al. Tu salud, ¡Si cuenta!: Exposure to a community-wide campaign and its associations with physical activity and fruit and vegetable consumption among individuals of Mexican descent. Soc Sci Med. 2015;143:98-106. doi: 10.1016/j.socscimed.2015.08.029

36. Vidoni ML, Lee M, Mitchell-Bennett L, Reininger BM, Vidoni ML. Home visit intervention promotes lifestyle changes: Results of an RCT in Mexican Americans. Am J Prev Med. 2019;57(5):611-620. doi: 10.1016/j.amepre.2019.06.020.

37. Green LW, Ottoson JM, García C, Hiatt RA. Diffusion theory and knowledge dissemination, utilization, and integration in public health. Annu Rev Public Health. 2009;30:151-174. doi: 10.1146/annurev.publhealth.031308.100049

38. Brownson R, Colditz G, Proctor E, Colditz G. The promise and challenges of dissemination and implementation research. In: Brownson R, Colditz G, Proctor E, Eds. Dissemination and implementation research in health: Translating science to practice. New York, NY: Oxford University Press; 2012 ; pp. 3-22.

39. Brownson RC, Colditz G, Proctor E, Rabin BA, Brownson R. Developing the terminology for dissemination and implementation research. In: Brownson RC, Colditz G, Proctor E, Eds. Dissemination and implementation research in health: Translating science to practice. 2nd ed. New York, NY: Oxford University Press; 2017; pp. 23-51.

40. Puska P, Vartiainen E, Laatikainen T, Jousilahti P, Paavola M, Eds. The North Karelia Project: From North Karelia to National Action. Helsinki, Finland: The National Institute for Health and Welfare (THL); 2009; pp. 85-102.

41. Puska P, Ståhl T. Health in All Policies - The Finnish Initiative: background, principles, and current issues. Ann Rev Public Health. 2010;31:315-328. doi: 10.1146/annurev.publhealth.012809.103658

42. Lewis BA, Napolitano MA, Buman MP, Williams DM, Nigg CR. Future directions in physical activity intervention research: expanding our focus to sedentary behaviors, technology, and dissemination. J Behav Med. 2017;40(1):112-126. doi: 10.1007/s10865-016-9797-8

43. Glasgow RE, Vogt TM, Boles SM. Evaluating the Public Health Impact of Health Promotion Interventions: The RE-AIM Framework. Am J Public Health. 1999;89:1322-1327.

44. Fisher-Hoch SP, Rentfro AR, Salinas JJ, Perez A, Brown HS, Reininger BM, Restrepo BI, Wilson JG, Hossain MM, Rahbar MH, Hanes CM. Socioeconomic status and prevalence of obesity and diabetes in a Mexican American community, Cameron County, Texas, 2004-2007. Preventing Chronic Disease. 2010;7(3):A53. http://www.cdc.gov/pcd/issues/2010/may/09_0170.htm

45. Ryabov I. Merino S. Recent Demographic Change in the Rio Grande Valley of Texas: The Importance of Domestic Migration. Journal of Borderlands Studies. 2017;2:211-231. doi: 10.1080/08865655.2016.1195704

46. United States Census Bureau. Poverty Status in the Past 12 Months. 2010 American Community Survey 1-Year Estimates Subject Tables. 2020. https://data.census.gov/cedsci/table?q=poverty\%20cameron\%20county\%20hidalgo\%20county\&tid=ACSST1Y2010.S1701. Accessed 25 August 2020.

47. Partners for Rural Transformation. Transforming Persistent Poverty in America: How Community Development Financial Institutions Drive Economic Opportunity. Robert Wood Johnson Foundation and NeighborWorks America. https://www.ruraltransformation.org/wpcontent/uploads/2020/03/Transforming_Persistent_Poverty_in_America__Policy-Paper-PRT-_FINAL.pdf. Accessed 22 May 2020.

48. Fisher-Hoch SP, Vatcheva KP, Rahbar MH, McCormick JB. Undiagnosed Diabetes and Pre-Diabetes in Health Disparities. PLoS One. 2015;10(7):e0133135. 10.1371/journal.pone.0133135.

49. United States Census Bureau. Poverty Status in the Past 12 Months. 2018 American Community Survey 5-Year Estimates Subject Tables. 2020. https://data.census.gov/cedsci/table?

q=brownsville,\%20harlingen,\%20los\%20fresnos,\%20san\%20benito,\%20hidalgo\%20county,\%20combes,\%20los\%20indios,\%20port\%20isabel,\%20rio\%20hor Accessed 27 August 2020.

50. Reininger BM, Barroso CS, Mitchell-Bennett L, et al. Process evaluation and participatory methods in an obesity-prevention media campaign for Mexican Americans. Health Promotion Practice. 2010;11(3):347-357. doi: 10.1177/1524839908321486

51. Larsen BA, Noble ML, Murray KE, et al. Physical activity in Latino men and women: facilitators, barriers, and interventions. American Journal of Life Medicine. 2014;9(1):4-30. doi: 10.1177/1559827614521758

52. Marcus BH, Dunsiger SI, Pekmezi DW, et al. The seamos saludables study: a randomized controlled physical activity trial of Latinas. Am J Prev Med. 2013;45(5):598-605. doi: 10.1016/j.amepre.2013.07.006 
53. Perales J, Reininger BM, Lee MJ, Linder SH. Participants' perceptions of interactions with community health workers who promote behavior change: a qualitative characterization from participants with normal, depressive, and anxious mood states. International Journal for Equity in Health. $2018 ; 17(1): 19$. doi: 10.1186/s12939-018-0729-9

54. Department of Health and Human Services. HHS Poverty Guidelines for 2020. Federal Register of the Department of Health and Human Services. 17 January 2020. https://aspe.hhs.gov/poverty-guidelines. Accessed 27 May 2020.

55. Cappuccio FP, Rink E, Perkins-Porras L, McKay C, Hilton S, Steptoe A. Estimation of fruit and vegetable intake using a two-item dietary questionnaire: a potential tool for potential tool for primary health care workers. Nutrition, Metabolism, and Cardiovascular Diseases 2003;13(1):12-19. doi: 10.1016/S0939-4753(03)80163-1

56. Godin G, Shephard RJ. Godin leisure-time exercise questionnaire. Medicine and Science in Sports and Exercise. 1997;29(6s):s36-s38.

57. Walker TJ, Heredia NI, Reininger BM. Examining the Validity, Reliability, and Measurement Invariance of the Social Support for Exercise Scale Among Spanish- and English-Language Hispanics. Hispanic Journal of Behavioral Sciences. 2019;41(3):427-443. doi: 10.1177/0739986319854144

58. Department of Health and Human Services. Physical Activity Guidelines for Americans: $2^{\text {nd }}$ United States Department of Health and Human Services. September 2019. https://health.gov/sites/default/files/2019-09/Physical_Activity_Guidelines_2nd_edition.pdf. Accessed 27 May 2020.

59. Beaudoin CE, Fernandez C, Wall JL, Farley TA. Promoting healthy eating and physical activity: short-term effects of a mass media campaign. American Journal of Preventive Medicine. 2007;32(3):217-223. doi: 10.1016/j.amepre.2006.11.002

60. Kamada M, Kitayuguchi J, Inoue S, Ishikawa Y, Nishiuchi H, Okada S, et al. A community-wide campaign to promote physical activity in middle-aged and elderly people: a cluster randomized controlled trial. International Journal of Behavioral Nutrition and Physical Activity. 2013;10:44. doi: 10.1186/14795868-10-44

61. Galaviz KI, Harden SM, Smith E, Blackman KCA, Berrey LM, Mama SK, Almeida FA, Lee RE, Estabrooks PA. Physical activity promotion in Latin American populations: a systematic review on issues of internal and external validity. International Journal of Behavioral Nutrition and Physical Activity. 2014;11:77. doi: 10.1186/1479-5868-11-77

62. Glasgow RE, Harden SM, Gaglio B, Rabin B, Smith ML, Porter GC, Ory MG, Estabrooks PA. RE-AIM Planning and Evaluation Framework: Adapting to New Science and Practice With a 20-Year Review. Front Public Health. 2019;7:64. doi: 10.3389/fpubh.2019.00064

63. Lee RE, Reese-Smith JY, Mama SK, Medina AV, Wolfe KL, Estabrooks PA. Reach and representativeness of ethnic minority women in the health is power study: a longitudinal analysis. Transl Behav Med. 2017;7:106-14. doi: 10.1007/s13142-016-0385-9

64. Vogt TM, Hollis JF, Lichtenstein E, et al. The medical care system and prevention: the need for a new paradigm. HMO Practice. 1998;12(1):5-13.

65. Kristein MM, Arnold CB, Wynder EL. Health economics and preventive care. Science. 1977; 195:457-462.

66. Hatziandreu EJ, Sacks JJ, Brown R, et al. The cost-effectiveness of three programs to increase use of bicycle helmets among children. Public Health Reports. 1995;110(3):251-259.

67. Reger B, Wootan MG, Booth-Butterfield S. A comparison of different approaches to promote community wide dietary change. Am J Prev Med. 2000;18:271-275. doi: 10.1016/S0749-3797(00)00118-5

68. Reger B, Wootan MG, BoothButterfield S, Smith H. 1\% or less: a community-based nutrition campaign. Public Health Reports. 1998;113(5):410-419.

69. Fortmann SP, Taylor CB, Flora JA, Winkleby MA. Effect of community health education on plasma cholesterol levels and diet: the Stanford Five-City Project. Am J Epidemiol. 1993;137:1039-1055.

70. Vanassema P, Steenbakkers M, Kok G, Eriksen M, Devries H. Results of the Dutch Community Project “Healthy Bergeyk”. Prev Med. 1994;23:394-401.

71. Mohammadifard N, Kelishadi R, Safavi M, et al. Effect of a community-based intervention on nutritional behaviour in a developing country setting: the Isfahan Healthy Heart Programme. Public Health Nutr. 2009;12:1422-1430. doi: 10.1017/S1368980008004230

72. Dergance, J. M., Mouton, C. P., Lichtenstein, M. J., \& Hazuda, H.P. Potential mediators of ethnic differences in physical activity in older Mexican Americans and European Americans: Results from the San Antonio longitudinal study of aging. Journal of the American Geriatrics Society. 2005;53(7):1240-1247. doi: 10.1111/j.1532-5415.2005.53363.x

73. Oppenheimer GM, Blackburn H, Puska P. From Framingham to North Karelia to U.S. Community-Based Prevention Programs: Negotiating Research Agenda for Coronary Heart Disease in the Second Half of the 20th Century. Public Health Reviews. 2011;33:450-483. doi: 10.1007/BF03391646

74. Leviton LC. Generalizing about public health interventions: a mixed-methods approach to external validity. Annu. Rev. Public Health. 2017;38:371-91. doi: 10.1146/annurev-publhealth-031816-044509

75. Rabin BA, Brownson RC, Kerner JF, Glasgow RE. Methodologic Challenges in Disseminating Evidence-Based Interventions to Promote Physical Activity. American Journal of Preventive Medicine. 2006;31(4):24-34. doi: 10.1016/j.amepre.2006.06.009

76. Rudd RE, Goldberg J, Dietz W. A Five-Stage Model for Sustaining a Community Campaign, Journal of Health Communication. 1999;4(1),37-48. doi: 10.1080/108107399127084

77. Knudsen HK, Drainoni ML, Gilbert L, Huerta TR, Oser CB, Aldrich AM, Campbell ANC, Crable EL, Garner BR, Glasgow LM, Goddard-Eckrich D, Marks KR, Scheck McAlearney A, Oga EA, Scalise AL, Walker DM. Model and approach for assessing implementation context and fidelity in the HEALing Communities Study. Drug and Alcohol Dependence. 2020;217:108330. doi: 10.1016/j.drugalcdep.2020.108330

78. Subar AF, Kirkpatrick SI, Mittl B, et al. The Automated Self-Administered 24-Hour Dietary Recall (ASA24): A Resource for Researchers, Clinicians and Educators from the National Cancer Institute. Journal of the Academy of Nutrition and Dietetics. 2012;112(8):1134-1137. doi: 10.1016/j.jand.2012.04.016

\section{Tables}

Page $12 / 16$ 


\section{Community- Operationalization of Component to promote fruit and vegetable (FV) consumption and physical activity (PA) \\ wide \\ Campaign \\ Components}

Mass and

Social Media

Delivery of regularly scheduled health promoting messages tailored to local culture and language (social media, radio, TV, print, text messaging) using behavioral journalism featuring local role models.

Social

Support and

Community-based groups tailored to local culture, language and identified health needs of community members including: 1) Exercise

Tailored and nutrition groups, 2) Weight loss and disease self-management support groups, 3) Health education programming in community

Health spaces, 4) Individualized motivational interviewing, 5) Motivational text messaging, 6) Home-based community health worker visits.

Education

Risk Factor Screening

Provision of free and accessible health risk screening in home and community locations for: 1) Blood Pressure, 2) BMI, 3) Referrals for glucose/HbA1c, 4) Referral and follow-up to clinical and social services.

Environmental Physical improvements identified and implemented by the locations including: 1) availability and access to produce through community Changes gardens and farmers markets, 2) activation of public spaces through free PA classes 3) community connectedness projects like sidewalks and trails, 4) safety and convenience projects like outdoor hydration and lighting

Policy Regulation improvements by locations including: 1) Complete street ordinances and healthy vending policies, 2) Improved school Improvements nutrition policies, 3) Active transportation policies

Table 2: Baseline characteristics of Latino participants enrolled in the TSCC Program $(n=5686)$

Variable

Low exposure $\quad(n=4639)$

Age, years, mean (SD)

$46.87(14.06)$

Female, N (\%)

$3644(77.49 \%)$

$1862(40.14 \%)$

Have insurance, $N(\%)$

Number of program strategies received ${ }^{b}, \quad$ median (IQR), [min, max]

$2(1,2)$

High exposure $\quad(n=1047)$

p-value ${ }^{a}$

Below federal poverty level, $\mathrm{N}(\%)$

Meeting PA guideline (600 MET) at Baseline, N (\%)

Meeting fruit \& vegetable guideline (> 4 portions) at Baseline, N (\%)

Baseline MET-minutes, mean (SD)

Baseline FV consumption, mean (SD)

$3312(84.22 \%)$

$1747(37.89 \%)$

$952(20.60 \%)$

166.35 (215.57)

$3.15(2.06)$

a Student's $t$-test or its non-parametric equivalent (i.e. Wilcoxon rank sum test) for continuous variables and Chi-square test for categorical variables were used.

${ }^{b}$ Number of program strategies received per participant has a range from 0 to 7 and includes newsletter, exercise classes, weight loss support groups, health education programming, motivational text messaging, and risk factor screening.

All participants received at least 2 community health worker home visits as part of the inclusion criteria for this study. 


\begin{tabular}{|c|c|c|c|c|c|c|c|c|}
\hline \multirow[b]{3}{*}{ Variable } & \multicolumn{4}{|c|}{$\begin{array}{l}\text { Change in Total FV consumption from baseline to the } \\
\text { last CHW visit }\end{array}$} & \multicolumn{4}{|c|}{$\begin{array}{l}\text { Change in Total PA MET-minutes from baseline } \\
\text { to the last CHW visit }\end{array}$} \\
\hline & \multicolumn{2}{|l|}{ Unadjusted } & \multicolumn{2}{|l|}{ Adjusted } & \multicolumn{2}{|l|}{ Unadjusted } & \multicolumn{2}{|l|}{ Adjusted } \\
\hline & $\begin{array}{l}\text { mean } \\
\text { difference in } \\
\text { change }\end{array}$ & $\begin{array}{l}\mathrm{P}- \\
\text { value }\end{array}$ & $\begin{array}{l}\text { mean } \\
\text { difference in } \\
\text { change }\end{array}$ & $\begin{array}{l}\mathrm{P}- \\
\text { value }\end{array}$ & $\begin{array}{l}\text { mean } \\
\text { difference in } \\
\text { change }\end{array}$ & $\begin{array}{l}\mathrm{P}- \\
\text { value }\end{array}$ & $\begin{array}{l}\text { mean } \\
\text { difference } \\
\text { in change }\end{array}$ & $\begin{array}{l}\mathrm{P}- \\
\text { value }\end{array}$ \\
\hline Exposure high vs. low & $\begin{array}{l}0.67(0.56 \\
0.79)\end{array}$ & $<.0001$ & $\begin{array}{l}0.65(0.53 \\
0.77)\end{array}$ & $<.0001$ & $\begin{array}{l}168.55 \\
(87.90 \\
249.21)\end{array}$ & $<.0001$ & $\begin{array}{l}185.62 \\
(105.87 \\
265.37)\end{array}$ & $<.0001$ \\
\hline \multirow[t]{2}{*}{$\begin{array}{l}\text { Estimated Mean change }(95 \% \text { CI) from } \\
\text { baseline to the last CHW visit in each group }\end{array}$} & \multirow{2}{*}{\multicolumn{2}{|c|}{$\begin{array}{l}\text { Low: } 0.63(0.58,0.67) \\
\text { High: } 1.30(1.20,1.40)\end{array}$}} & \multirow{2}{*}{\multicolumn{2}{|c|}{$\begin{array}{l}\text { Low: } 0.73(0.65,0.80) \\
\text { High: } 1.38(1.26,1.50)\end{array}$}} & \multirow{2}{*}{\multicolumn{2}{|c|}{$\begin{array}{l}\text { Low: } 138.14 \text { (106.45, } \\
\text { 169.83) } \\
\text { High: } 306.69 \text { (234.67, } \\
\text { 378.72) }\end{array}$}} & \multirow{2}{*}{\multicolumn{2}{|c|}{$\begin{array}{l}\text { Low: } 210.67 \\
\text { (162.09, 259.26) } \\
\text { High: } 396.29 \\
(316.80,475.79)\end{array}$}} \\
\hline & & & & & & & & \\
\hline \multicolumn{3}{|l|}{ \# program strategies received } & $\begin{array}{l}0.16(0.12 \\
0.20)\end{array}$ & $<.0001$ & & & $\begin{array}{l}147.77 \\
(120.83 \\
174.72)\end{array}$ & $<.0001$ \\
\hline \multicolumn{3}{|l|}{ Age, year } & $\begin{array}{l}0.002(-0.001 \\
0.005)\end{array}$ & 0.1663 & & & $\begin{array}{l}-9.26 \\
(-11.28 \\
-7.25)\end{array}$ & $<.0001$ \\
\hline \multicolumn{3}{|l|}{ Sex female vs. male } & $\begin{array}{l}-0.06(-0.16 \\
0.04)\end{array}$ & 0.2438 & & & $\begin{array}{l}-30.21 \\
(-98.24 \\
37.82)\end{array}$ & 0.3840 \\
\hline \multicolumn{3}{|l|}{ Have insurance yes vs. no } & $\begin{array}{l}0.39(0.29 \\
0.49)\end{array}$ & $<.0001$ & & & $\begin{array}{l}161.72 \\
(95.14 \\
228.30)\end{array}$ & $<.0001$ \\
\hline \multicolumn{3}{|l|}{ Poverty status below vs. above FPL } & $\begin{array}{l}0.05(-0.07 \\
0.18)\end{array}$ & 0.3789 & & & $\begin{array}{l}-66.04 \\
(-147.10 \\
-15.02)\end{array}$ & 0.1103 \\
\hline \multicolumn{9}{|c|}{$\begin{array}{l}\text { Abbreviations: CHW, community health worker; FV, fruit and vegetable; MET, metabolic equivalents; PA, physical activity; TSSC, Tu Salud ;Si Cuenta! } \\
\text { program. }\end{array}$} \\
\hline \multicolumn{9}{|c|}{$\begin{array}{l}\text { High program exposure defined as participants having 4-5 CHW visits (3-4 follow-up visits). Low program exposure defined as participants having } 2-3 \\
\text { CHW visits ( } 1-2 \text { follow-up visits). }\end{array}$} \\
\hline
\end{tabular}

Table 4. TSSC program effect on meeting FV and PA guideline based logistic regression analysis

\begin{tabular}{|c|c|c|c|c|c|c|c|c|}
\hline \multirow[b]{3}{*}{ Variable } & \multicolumn{4}{|c|}{ Meeting FV guideline by last $\mathrm{CHW}$ visit $(n=4411)$} & \multicolumn{4}{|c|}{ Meeting PA guideline by last $\mathrm{CHW}$ visit $(n=3429)$} \\
\hline & \multicolumn{2}{|l|}{ Unadjusted } & \multicolumn{2}{|l|}{ Adjusted } & \multicolumn{2}{|l|}{ Unadjusted } & \multicolumn{2}{|l|}{ Adjusted } \\
\hline & $\begin{array}{l}\text { Odds Ratio }(95 \% \\
\text { Cl) }\end{array}$ & $\begin{array}{l}\mathrm{P} \text { - } \\
\text { value }\end{array}$ & $\begin{array}{l}\text { Odds Ratio (95\% } \\
\text { Cl) }\end{array}$ & $\begin{array}{l}\mathrm{P} \text { - } \\
\text { value }\end{array}$ & $\begin{array}{l}\text { Odds Ratio }(95 \% \\
\text { Cl) }\end{array}$ & $\begin{array}{l}\mathrm{P} \text { - } \\
\text { value }\end{array}$ & $\begin{array}{l}\text { Odds Ratio } \\
(95 \% \mathrm{Cl})\end{array}$ & $\begin{array}{l}\mathrm{P} \text { - } \\
\text { value }\end{array}$ \\
\hline Exposure high vs. low & $2.00(1.64,2.43)$ & $<.0001$ & $2.02(1.65,2.47)$ & $<.0001$ & $1.24(1.10,1.54)$ & 0.0393 & $1.36(1.10,1.68)$ & 0.0046 \\
\hline \multicolumn{3}{|l|}{$\begin{array}{l}\text { \# program strategies } \\
\text { received }\end{array}$} & $1.30(1.22,1.39)$ & $<.0001$ & & & $1.18(1.10,1.26)$ & $<.0001$ \\
\hline \multicolumn{3}{|l|}{ Age, year } & $1.00(1.00,1.01)$ & 0.2430 & & & $0.98(0.97,0.98)$ & $<.0001$ \\
\hline \multicolumn{3}{|l|}{ Sex female vs. male } & $1.18(0.98,1.42)$ & 0.0737 & & & $1.35(1.12,1.61)$ & 0.0014 \\
\hline \multicolumn{3}{|l|}{ Have insurance yes vs. no } & $1.24(1.04,1.48)$ & 0.0151 & & & $1.36(1.15,1.63)$ & 0.0004 \\
\hline \multicolumn{3}{|l|}{$\begin{array}{l}\text { Poverty status below vs. } \\
\text { above FPL }\end{array}$} & $1.02(0.82,1.26)$ & 0.8951 & & & $0.73(0.59,0.91)$ & 0.0005 \\
\hline \multicolumn{9}{|c|}{$\begin{array}{l}\text { Abbreviations: CHW, community health worker; FV, fruit and vegetable; MET, metabolic equivalents; PA, physical activity; TSSC, Tu Salud ;Si Cuenta! } \\
\text { program. }\end{array}$} \\
\hline \multicolumn{9}{|c|}{$\begin{array}{l}\text { High program exposure defined as participants having } 4-5 \mathrm{CHW} \text { visits (3-4 follow-up visits). Low program exposure defined as participants having } 2-3 \\
\mathrm{CHW} \text { visits (1-2 follow-up visits). }\end{array}$} \\
\hline
\end{tabular}


Table 5. TSSC program effect on change in FV, PA MET-minutes and meeting FV, PA guideline by location

Change in Total FV consumption from baseline to the last $\mathrm{CHW}$ visit

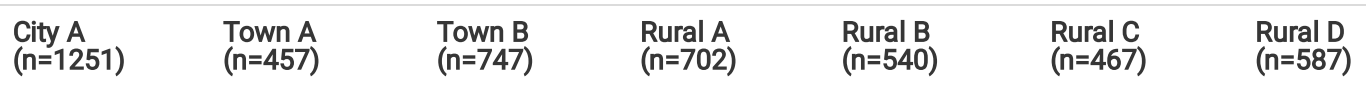

Adjusted mean difference in change and $95 \%$ confidence interval with p-value

\begin{tabular}{|c|c|c|c|c|c|c|c|}
\hline Exposure high vs. low & $\begin{array}{l}0.63(0.37 \\
0.88) \\
p<0.0001\end{array}$ & $\begin{array}{l}1.45(0.71 \\
2.19) \\
p<0.0001\end{array}$ & $\begin{array}{l}0.62(0.37 \\
0.88) \\
p<0.0001\end{array}$ & $\begin{array}{l}0.63(0.44 \\
0.83) \\
p<0.0001\end{array}$ & $\begin{array}{l}0.71(0.17 \\
1.24) \\
p=0.0097\end{array}$ & $\begin{array}{l}0.74(0.24 \\
1.26) \\
p=0.0041\end{array}$ & $\begin{array}{l}0.44(0.06 \\
0.82) \\
p=0.0242\end{array}$ \\
\hline \multirow{2}{*}{$\begin{array}{l}\text { Estimated Mean change }(95 \% \text { CI) } \\
\text { from baseline to the last CHW visit } \\
\text { in each group }\end{array}$} & $\begin{array}{l}\text { Low: } 0.66 \\
(0.48,0.83)\end{array}$ & $\begin{array}{l}\text { Low: } 0.68 \\
(0.27,1.09)\end{array}$ & $\begin{array}{l}\text { Low: } 0.53 \\
(0.40,0.65)\end{array}$ & $\begin{array}{l}\text { Low: } 0.73 \\
(0.58,0.89)\end{array}$ & $\begin{array}{l}\text { Low: } 0.91 \\
(0.61,1.22)\end{array}$ & $\begin{array}{l}\text { Low: } 1.45 \\
(1.01,1.90)\end{array}$ & $\begin{array}{l}\text { Low: } 0.55 \\
(0.03,1.08)\end{array}$ \\
\hline & $\begin{array}{l}\text { High: } 1.28 \\
(1.03,1.53)\end{array}$ & $\begin{array}{l}\text { High: } 2.13 \\
(1.31,2.95)\end{array}$ & $\begin{array}{l}\text { High: } 1.15 \\
(0.94,1.36)\end{array}$ & $\begin{array}{l}\text { High: } 1.37 \\
(1.23,1.50)\end{array}$ & $\begin{array}{l}\text { High: } 1.62 \\
(1.06,2.18)\end{array}$ & $\begin{array}{l}\text { High: } 2.20 \\
(1.50,2.91)\end{array}$ & $\begin{array}{l}\text { High: } 0.99 \\
(0.39,1.59)\end{array}$ \\
\hline
\end{tabular}

Meeting FV guideline at the last CHW visit

\begin{tabular}{|c|c|c|c|c|c|c|c|}
\hline & $\begin{array}{l}\text { City A } \\
(n=708)\end{array}$ & $\begin{array}{l}\text { Town A } \\
(n=304)\end{array}$ & $\begin{array}{l}\text { Town B } \\
(n=422)\end{array}$ & $\begin{array}{l}\text { Rural A } \\
(n=406)\end{array}$ & $\begin{array}{l}\text { Rural B } \\
(n=307)\end{array}$ & $\begin{array}{l}\text { Rural C } \\
(n=322)\end{array}$ & $\begin{array}{l}\text { Rural D } \\
(n=432)\end{array}$ \\
\hline & \multicolumn{7}{|c|}{ Adjusted Odds Ratio and 95\% confidence interval with p-value } \\
\hline Exposure high vs. low & $\begin{array}{l}2.04(1.41 \\
2.96) \\
p=0.0002\end{array}$ & $\begin{array}{l}1.97(0.77 \\
5.06) ; \\
p=0.1567\end{array}$ & $\begin{array}{l}0.84(0.38 \\
1.84) \\
p=0.6636\end{array}$ & $\begin{array}{l}3.98(2.19 \\
7.24) \\
p<0.0001\end{array}$ & $\begin{array}{l}2.40(1.20 \\
4.82) \\
p=0.0135\end{array}$ & $\begin{array}{l}4.10(1.36 \\
12.45) \\
p=0.0125\end{array}$ & $\begin{array}{l}2.73(0.94 \\
7.94) \\
p=0.0652\end{array}$ \\
\hline \multicolumn{8}{|c|}{ Change in Total PA MET-minutes from baseline to the last $\mathrm{CHW}$ visit } \\
\hline & $\begin{array}{l}\text { City A } \\
(n=1251)\end{array}$ & $\begin{array}{l}\text { Town A } \\
(n=456)\end{array}$ & $\begin{array}{l}\text { Town B } \\
(n=747)\end{array}$ & $\begin{array}{l}\text { Rural A } \\
(n=702)\end{array}$ & $\begin{array}{l}\text { Rural B } \\
(n=540)\end{array}$ & $\begin{array}{l}\text { Rural C } \\
(n=467)\end{array}$ & $\begin{array}{l}\text { Rural D } \\
(n=587)\end{array}$ \\
\hline & \multicolumn{7}{|c|}{ Adjusted mean difference in change and $95 \%$ confidence interval with $p$-value } \\
\hline Exposure high vs. low & $\begin{array}{l}38.55(-102 \\
20,179.30) \\
\mathrm{p}=0 . .5911\end{array}$ & $\begin{array}{l}897.62 \\
(541.05 \\
1254.19) \\
p<0.0001\end{array}$ & $\begin{array}{l}-171.11( \\
-345.97 \\
3.74) \\
p=0.0551\end{array}$ & $\begin{array}{l}220.38 \\
(65.05 \\
375.70) ; \\
p=0.0055\end{array}$ & $\begin{array}{l}-147.53 \\
(-345.83 \\
50.76) \\
p=0.1445\end{array}$ & $\begin{array}{l}290.94 \\
(-55.44 \\
637.33) ; \\
p=0.0995\end{array}$ & $\begin{array}{l}189.59 \\
(-122.59 \\
501.65) \\
p=0.2333\end{array}$ \\
\hline \multirow[t]{2}{*}{$\begin{array}{l}\text { Estimated Mean change }(95 \% \text { Cl) } \\
\text { from baseline to the last CHW visit } \\
\text { in each group }\end{array}$} & $\begin{array}{l}\text { Low: }-3.91 \\
(-103.26 \\
95.45)\end{array}$ & $\begin{array}{l}\text { Low: } 512.21 \\
(350.98 \\
673.45)\end{array}$ & $\begin{array}{l}\text { Low: } 48.52 \\
(-42.99 \\
140.02)\end{array}$ & $\begin{array}{l}\text { Low: } 577.68 \\
(458.00 \\
697.35)\end{array}$ & $\begin{array}{l}\text { Low: } 155.81 \\
(42.09 \\
269.54)\end{array}$ & $\begin{array}{l}\text { Low: } 295.99 \\
(-5.86, \\
597.84)\end{array}$ & $\begin{array}{l}\text { Low: }-213.82 \\
(-706.87 \\
278.22)\end{array}$ \\
\hline & $\begin{array}{l}\text { High: } 34.64 \\
(-104.02 \\
173.31)\end{array}$ & $\begin{array}{l}\text { High: } 1409.83 \\
\text { (1031.81, } \\
1787.85)\end{array}$ & $\begin{array}{l}\text { High: } \\
-122.60 \\
(-308.31, \\
63.11)\end{array}$ & $\begin{array}{l}\text { High: } 798.06 \\
\text { (692.83, } \\
\text { 903.28) }\end{array}$ & $\begin{array}{l}\text { High: } 8.28 \\
(-199.60, \\
216.16)\end{array}$ & $\begin{array}{l}\text { High: } 586.94 \\
\text { (107.68, } \\
1066.19)\end{array}$ & $\begin{array}{l}\text { High: }-24.24 \\
(-456.66, \\
408.15)\end{array}$ \\
\hline \multicolumn{8}{|c|}{ Meeting FV guideline at the last $\mathrm{CHW}$ visit } \\
\hline & $\begin{array}{l}\text { City A } \\
(n=1007)\end{array}$ & $\begin{array}{l}\text { Town A } \\
(n=361)\end{array}$ & $\begin{array}{l}\text { Town B } \\
(n=608)\end{array}$ & $\begin{array}{l}\text { Rural A } \\
(n=445)\end{array}$ & $\begin{array}{l}\text { Rural B } \\
(n=375)\end{array}$ & $\begin{array}{l}\text { Rural C } \\
(n=375)\end{array}$ & $\begin{array}{l}\text { Rural D } \\
(n=511)\end{array}$ \\
\hline & \multicolumn{7}{|c|}{ Adjusted Odds Ratio and 95\% confidence interval with p-value } \\
\hline Exposure high vs. low & $\begin{array}{l}1.15(0.73 \\
1.82) ; \\
p=0.5382\end{array}$ & $\begin{array}{l}3.84(1.05 \\
13.95) ; \\
p=0.0414\end{array}$ & $\begin{array}{l}1.38(0.56 \\
3.39) \\
p=0.4903\end{array}$ & $\begin{array}{l}2.42(1.35 \\
4.32) ; \\
p=0.0029\end{array}$ & $\begin{array}{l}1.00(0.47 \\
2.10) \\
p=0.9923\end{array}$ & $\begin{array}{l}5.41(1.62 \\
18.08) \\
p=0.0061\end{array}$ & $\begin{array}{l}1.14(0.42 \\
3.08) \\
p=0.7933\end{array}$ \\
\hline \multicolumn{8}{|c|}{$\begin{array}{l}\text { Abbreviations: CHW, community health worker; FV, fruit and vegetable; MET, metabolic equivalents; PA, physical activity; TSSC, Tu Salud ;Si Cuenta! } \\
\text { program. }\end{array}$} \\
\hline \multicolumn{8}{|c|}{$\begin{array}{l}\text { High program exposure defined as participants having } 4-5 \mathrm{CHW} \text { visits (3-4 follow-up visits). Low program exposure defined as participants having } 2-3 \\
\mathrm{CHW} \text { visits (1-2 follow-up visits). Linear regression models were performed for the mean difference in the change of FV and PA in each location. Logistic } \\
\text { regression models were performed on all individuals who did not meet FV or PA guidelines at baseline in each location. }\end{array}$} \\
\hline
\end{tabular}

\section{Figures}


Tu Salud iSi Cuenta! Study Design: Each year people were enrolled serving as their own control. Sample size only represents individuals with enrollment plus a minimum of 2 additional outcome visits

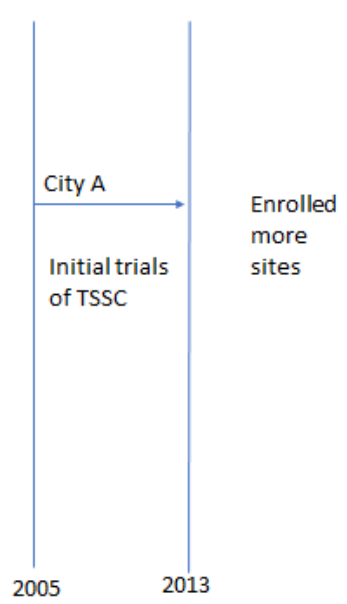

City A $\quad(n=1251)$

ghlighted sites included in location specific analysis with sufficient sample size

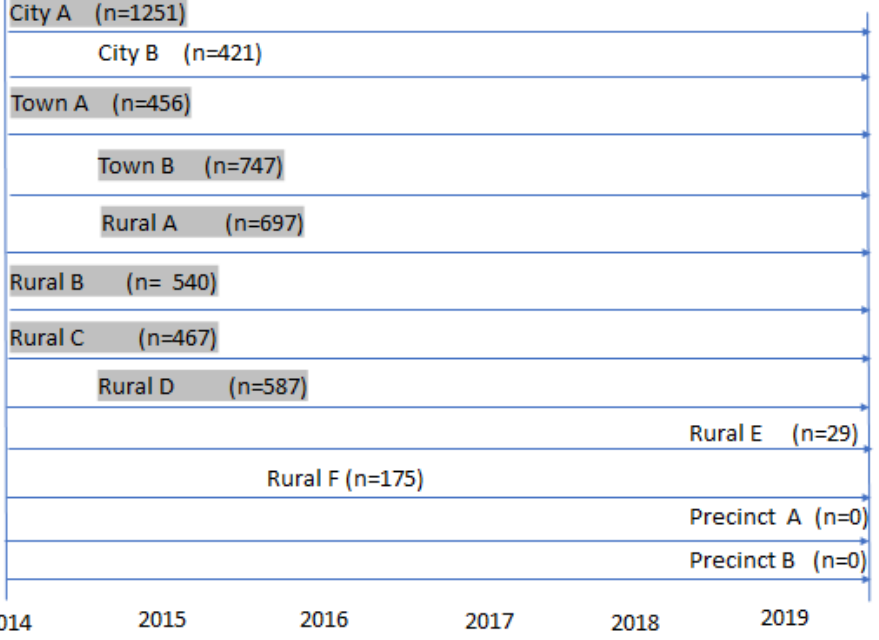

\section{Figure 1}

Tu Salud ¡Si Cuenta! Study Design 